\title{
2 Die Achsenverbündeten und der Balkan: Ideologien, Visionen und Pläne
}

Bevor die Besatzungspraxis der deutschen und der italienischen Besatzer untersucht und verglichen wird, müssen die jeweiligen Ideologien und die daraus resultierenden (Expansions-)Pläne für den Balkan, den jugoslawischen Raum und speziell für den Unabhängigen Staat Kroatien betrachtet und einander gegenübergestellt werden. Denn diese Vorstellungen waren es, wie im weiteren Verlauf der Studie gezeigt wird, die nicht nur die Richtung der politischen Entscheidungen vorgaben, sondern auch das Verhalten der einzelnen politischen und militärischen Vertreter vor Ort prägten.

Die Neuordnung Europas und die Expansion nach Osten bildeten eines der wichtigsten deutschen Kriegsziele. Daher ist bei der Untersuchung der deutschen Besatzungen in ganz Europa stets der Platz, den die Nationalsozialisten in ihrer Vision der „neuen Ordnung“ dem jeweiligen Gebiet sowie der dort lebenden Bevölkerung zuwiesen, von entscheidender Bedeutung. Diese „Neuordnung“ Europas sollte auf der rassischen Grundlage erfolgen. Die ihnen vorschwebende Verbindung von Territorialität und (Um)siedlungspolitik auf der Basis von rassenbiologischen Vorstellungen bezeichneten sie dabei als „Flurbereinigung“. Anders als Preußen oder der Bündnispartner Italien, verfolgte das Dritte Reich niemals eine Germanisierung, die auf kultureller Vorherrschaft gründete. Nach Ansicht der Nationalsozialisten konnte nur der Boden „germanisiert" werden, indem er mit Germanen besiedelt wurde. ${ }^{1}$ So sind die Verbrechen gegen die Zivilbevölkerung in Polen untrennbar mit dem Plan verbunden, den Großteil des polnischen Gebietes zu annektieren und den Großteil der polnischen Bevölkerung zu vernichten - entweder sofort oder erst nach der Ausnutzung ihrer Arbeitskraft. ${ }^{2}$ Das Aushungern der Bevölkerung etwa in der Ukraine ist ohne die Einbeziehung des Generalplans Ost nicht zu erklären. ${ }^{3}$

\footnotetext{
1 Wildt, Michael: Völkische Neuordnung Europas, in: Themenportal Europäische Geschichte, 2007, www.europa.clio-online.de/essay/id/artikel-3332 (6.5.2019); Hass, Gerhart: Weltkrieg Okkupation - Genozid, in: Röhr, Werner (Hg.): Faschismus und Rassismus, Berlin 1992, S. 239-256, hier S. 251; Wirsching, Andreas: „Man kann nur Boden germanisieren“. Eine neue Quelle zu Hitlers Rede vor den Spitzen der Reichswehr am 3. Februar 1933, in: Vierteljahrshefte für Zeitgeschichte 49 (2001) 3, S. 517-550.

2 Młynarczyk, Jacek Andrzej (Hg.): Polen unter deutscher und sowjetischer Besatzung: 19391945, Osnabrück 2009; Böhler, Jochen/Lehnstaedt, Stephan (Hg.): Gewalt und Alltag im besetzten Polen 1939-1945 (Ergebnisse einer Konferenz vom 20. - 22. November 2009 in Warschau), Osnabrück 2012; Wolf, Gerhard: Ideologie und Herrschaftsrationalität: nationalsozialistische Germanisierungspolitik in Polen, Hamburg 2012.
} 
Trotz dieser Neuordnungspläne, wurden im Vorfeld der Feldzüge in Südosteuropa keine Pläne entworfen, die die Ermordung bzw. den Hungertot von Tausenden oder Millionen Menschen vorsahen, wie es für die Sowjetunion der Fall war. ${ }^{4}$ Der Generalplan Ost sah die Neuordnung des osteuropäischen Raumes von Polen bis zum Ural vor - außen vor blieb dabei der südosteuropäische Raum. Nur im Generalsiedlungsplan vom September 1942 wurde die Aussiedlung der Slowenen aus Krain und die Ansiedlung der Deutschen aus der Götschee anvisiert und dann auch umgesetzt. Eine darüber hinausgehende Ansiedlung von Deutschen in Südosteuropa wurde nicht erwogen. ${ }^{5}$

Auch Italien hatte eigene Pläne für sich und die angrenzenden Länder in der „neuen Ordnung“, die es mit Deutschland gemeinsam gestalten wollte. So wie Deutschland ein besonderes Interesse am „Osten“ hatte, stellten Nordafrika und der Balkan klassische Ziele der italienischen Expansionspolitik dar. Italienische Pläne, das sollte sich auch in Kroatien zeigen, waren jedoch nicht zwangsläufig mit den Plänen der Deutschen kompatibel.

Ein fundamentaler Unterschied zwischen dem deutschen Nationalsozialismus und dem italienischen Faschismus lag darin, wie die Nation konzipiert wurde. Dem deutschen Expansionskonzept setzten die Faschisten ein römischmediterranes geopolitisches Konzept entgegen, das sich auf das antike Römische Imperium berief. Die italienische Nation war nach faschistischer Ausle-

3 Gerlach, Christian: Kalkulierte Morde. Die deutsche Wirtschafts- und Vernichtungspolitik in Weißrußland 1941 bis 1944, Hamburg 2000; Kay, Alex: Exploitation, Resettlement, Mass Murder: Political and Economic Planning for German Occupation Policy in the Soviet Union, 19401941, New York/Oxford 2006; Berkhoff, Karel C: „Wir sollen verhungern, damit Platz für die Deutschen geschaffen wird“. Hungersnöte in den ukrainischen Städten im Zweiten Weltkrieg, in: Quinkert, Babette (Hg.): Deutsche Besatzung in der Sowjetunion: 1941-1944. Vernichtungskrieg, Reaktionen, Erinnerung, Paderborn 2014, S. 54-75.

4 Aly, Götz/Heim, Susanne: Vordenker der Vernichtung. Auschwitz und die deutschen Pläne für eine neue europäische Ordnung, S. 369 f. Die Mitarbeiter des Generalrats der Vierjahresplanbehörde gingen von 30 Mio. sowjetischen Toten aus, um den deutschen Fleischkonsum und damit die „gute Stimmung“ zu garantieren. Genauso sahen die „Wirtschaftspolitischen Richtlinien für die Wirtschaftsorganisation Ost, Gruppe Landwirtschaft“ den Hungertod für „viele 10 Millionen Menschen“ vor. Aly/Heim: Vordenker der Vernichtung, S. $372 \mathrm{f}$.

5 So behandelt auch Isabel Heinemann in ihrer 600 Seiten starken Abhandlung zur rassenpolitischen Neuordnung Europas Südosteuropa nicht. Siehe Heinemann, Isabel: „Rasse, Siedlung, deutsches Blut“. Das Rasse- und Siedlungshauptamt der SS und die rassenpolitische Neuordnung Europas, Göttingen 2003. Zur Umsiedlung der Slowenen verfasste sie jedoch einen Aufsatz: Heinemann, Isabel: Die Rasseexperten der SS und die bevölkerungspolitische Neuordnung Südosteuropas, in: Mathias Beer ... [et al.] (Hg.): Südostforschung im Schatten des Dritten Reiches: Institutionen - Inhalte - Personen, München 2004, S. 135-158; Ferenc, Tone: Nacistička politika denacionalizacije u Sloveniji u godinama od 1941. do 1945, Ljubljana-Beograd 1979. 
gung anderen europäischen Nationen aufgrund ihrer Geschichte und ihrer höherstehenden Kultur überlegen, nicht aufgrund ihrer Rasse. ${ }^{6}$ Das sich vom Dritten Reich und seiner „Neuen Ordnung“ bedrohte Italien ging ab Ende der dreißiger Jahre dazu über, ein eigenes Europakonzept, das als Gegenkonzept zu dem nationalsozialistischen verstanden wurde, aufzubauen. Den Kern dieses Konzepts bildete die Betonung der italienischen civiltà, in Abgrenzung zur germanischen „Barbarei“.7 So erklärte Francesco Orestano in der von Mussolini gegründeten Zeitschrift Gerarchia mit einer deutlichen Spitze gegen Deutschland, dass eine „Neue Ordnung“ nicht auf der Grundlage der „Superrasse, des Supernationalismus oder des Superstaates“ begründet werden könne. ${ }^{8}$

Für diese von Italien aus zu errichtende imperiale Gesellschaft war eine hierarchische Neuordnung Europas vorgesehen. Hierbei wurde zwischen dem Kernland Italien mit allen annektierten Gebieten und den übrigen zum Imperium gehörenden Territorien unterschieden. ${ }^{9}$ In einem Artikel in der Critica fascista von 1942 wurde etwa erwogen, in Europa von Rom abhängige Protektorate und Satelliten $\mathrm{zu}$ schaffen. Hierbei war nicht vorgesehen, dass deren Bevölkerungen Platz für italienische Siedler machen sollten, obschon durchaus Vorstellungen von Bevölkerungstransfers und Vertreibungen in der faschistischen Vision des Imperiums diskutiert wurden: Die Lebensräume, so der Autor Salvatore Villari, seien nichts anderes als die territoriale Ausbreitung des Imperiums. Darin würden einige Regionen weiterhin den Status von echten Staaten innehaben, wohingegen andere in (italienische) Besitztümer und Kolonien umgewandelt würden. ${ }^{10}$ Mit solchen Ideen standen die italienischen Faschisten dem englischen und französischen Imperialismus des 19. Jahrhunderts deutlich näher als der nationalsozialistischen Ideologie vom Lebensraum, der für das deutsche Herrenvolk erobert werden sollte. ${ }^{11}$

Diese Unterschiede können auch am kroatischen Beispiel nachvollzogen werden. Obwohl das Dritte Reich eher vage Pläne für den Südosten Europas hat-

6 Kallis, Aristotle: Fascist Ideology. Territory and Expansionism in Italy and Germany, 19221945, S. 43; Antonsich, Marco: La rivista „Geopolitica“ e la sua influenza sulla politica fascista, in: Limes. Rivista italiana di geopolitica, (1994) 4, S. 269-279, hier S. 275 f.

7 Fioravanzo: Europakonzeptionen, insbesondere S. 525-533; Hoffend, Andrea: „Verteidigung des Humanismus"? Der italienische Faschismus vor der kulturellen Herausforderung durch den Nationalsozialismus, in: Petersen, Jens/Schieder, Theodor (Hg.): Faschismus und Gesellschaft in Italien. Staat-Wirtschaft-Kultur, Köln 1998, S. 177-198.

8 Orestano, Francesco: „Nuovo ordine Europeo“, in: Gerarchia, 21, (1942), 1, S. 3-9, hier S. 5-7. 9 Gentile, Emilio: La nazione del fascismo, S. 95; Gentile: La Grande Italia, S. 180 f.

10 Villari, Salvatore: Principi giuridici per il nuovo ordine, in: Critica fascista, 20 (1941/42) 4, S. 50-53, hier S. 51.

11 Vgl. auch Rodogno: Sogni di conquista, S. 116 f.; Osti Guerrazzi, Amedeo: Noi non sappiamo odiare. L'esercito italiano tra fascismo e democrazia, Turin 2010, S. 265. 
te, während diejenigen Italiens deutlich konkreter waren, bestimmten diese von Anfang an das Verhalten beider Achsenpartner vor Ort. Je mehr sich Italien aufgrund der militärischen Schwäche zu einem Juniorpartner Deutschlands entwickelte und die Möglichkeit einer „Faschistisierung“ eines Teils Europas schwand, umso mehr achteten seine Vertreter auf die offizielle Anerkennung seines spazio vitale. Dies führte dazu, dass das Streben der Achsenpartner manchmal einander diametral entgegengesetzt war, während sie bei anderen Entscheidungen wieder am gleichen Strang zogen.

\subsection{Der Südosten in den deutschen Zukunftsplänen}

Die Erweiterung des Lebensraums des Deutschen Volkes war eines der Hauptelemente des Nationalsozialismus. Hitler und seine Ideologen hatten von vornherein in den Weiten des europäischen Ostens, in Polen und der Sowjetunion, ihren Lebensraum ausgemacht. Nachdem die Nationalsozialisten an die Macht gekommen waren, erarbeiteten sie umfassende Expansionspläne. Diese bauten auf einer Rassenideologie auf, die auf dem biologischen Rassismus beruhte. Demnach war das Blut der Träger der Eigenschaften eines Volkes und die Völker wurden nach diesem Prinzip hierarchisch eingeteilt. An der Spitze stand der nordische Arier, ganz unten auf der Rassenskala befanden sich die Juden. Dazwischen gab es zahlreiche Abstufungen. Nach dieser Ideologie stand nicht die Eroberung anderer Staaten und ihre Ausbeutung im klassisch kolonialistischen Sinn in Zentrum, sondern ihre „Germanisierung“. Die Einstufung in unterschiedliche „Rassen“ besiegelte zumindest in der Theorie das Schicksal der Menschen. Für die Slawen in Osteuropa bedeutete dies, dass sie den ankommenden deutschen Siedlern weichen sollten - ein großer Teil sollte getötet, ein anderer weiter nach Osten vertrieben werden, während die übrigen den Deutschen dienen sollten. Nur ein kleiner Teil, nämlich jene, die als „eindeutschungsfähig“ eingestuft wurden, waren für die Germanisierung vorgesehen. Gegenüber Juden sowie Sinti und Roma verfolgten die Nationalsozialisten in ihrem gesamten Machtbereich eine Politik der Vernichtung. ${ }^{12}$

12 Hillgruber, Andreas: Die „Endlösung“ und das deutsche Ostimperium als Kernstück des rassenideologischen Programms des Nationalsozialismus, in: Vierteljahrshefte für Zeitgeschichte 20 (1972) 2, S. 133-153; Wildt, Michael: Die Generation des Unbedingten. Das Führungskorps des Reichssicherheitshauptamtes, Hamburg 2002, S. 654-670; Mai, Uwe: Rasse und Raum. Agrarpolitik, Sozial- und Raumplanung im NS-Staat, Paderborn 2002; Heinemann, Isabell/Wagner, Patrick (Hg.): Wissenschaft, Planung, Vertreibung: Neuordnungskonzepte und Umsiedlungspolitik im 20. Jahrhundert, Stuttgart 2006; Gerhard, Gesine: Food and Genocide. 
So ausgearbeitet und umfangreich die Pläne für den europäischen Osten waren, so rudimentär waren sie im Hinblick auf Südosteuropa und seine zukünftige Rolle in der „Neuen Ordnung“. Hitler hat sich dazu sowohl vor, als auch nach 1941 kaum geäußert. Das gesamte Gebiet spielte im Vergleich zum primären Ziel der Verschiebung der Ostgrenzen nur eine untergeordnete Rolle. ${ }^{13}$ Für die Eroberung von „Lebensraum“ im Osten sollte die südosteuropäische Wirtschaft unter deutsche Kontrolle gebracht werden, da der deutsche Wirtschaftsraum für den kommenden Krieg allein nicht über genügend Ressourcen verfügte. Doch bei allen ökonomischen Überlegungen waren die rassistischen Denkmuster der Nationalsozialisten ebenfalls stets präsent. Die deutschen brachten ein Überlegenheitsgefühl gegenüber den Slawen des Balkans mit. So schloss die ökonomische auch eine politische Abhängigkeit der „schwachen“ also „rassisch minderwertigeren“ Völker des Südostens von dem „Führungsvolk" ein. ${ }^{14}$ Dies galt aufgrund der historischen Gegebenheiten aus dem Ersten Weltkrieg insbesondere für Serben. ${ }^{15}$ Auch gegenüber den „muslimischen Kroaten" lassen sich kulturelle Vorurteile ausmachen. Andererseits waren und blieben die Kroaten deutsche Verbündete. Auch die auf die deutschen Soldaten zugeschnittene Propaganda zeigt, dass die Kroaten nie auf eine Stufe mit Polen oder Russen gesetzt wurden. ${ }^{16}$

Die südosteuropäischen Völker hatten zunächst das Glück, nicht in Hitlers unmittelbarem Eroberungsgebiet zu leben. Der deutsche politische Einfluss soll-

Nazi Agrarian Politics in the Occupied Territories of the Soviet Union, in: Contemporary European History, 18 (2009) 1, S. 45-65.

13 Vgl. auch Fleischer, Hagen: Nationalsozialistische Besatzungsherrschaft im Vergleich: Versuch einer Synopse, in: Benz, Wolfgang/ Houwink ten Cate, Johannes/Otto, Gerhard (Hg.): Anpassung, Kollaboration, Widerstand. Kollektive Reaktionen auf die Okkupation, Berlin 1996, S. 257-302, hier S. 269, 283.

14 Ristović: Nemački novi poredak, S. 12 f.; Sundhaussen: Okkupation, Kollaboration und Widerstand, S. 349, Deist, Wilhelm/Messerschmidt, Manfred/Volkmann, Hans-Ulrich/Wette, Wolfram: Ursachen und Voraussetzungen der Deutschen Kriegspolitik, Stuttgart 1979, S. 675. Benz, Wolfgang: Typologie der Herrschaftsformen in den Gebieten unter deutschem Einfluß, in: Benz, Wolfgang/Houwink ten Cate, Johannes/Otto, Gerhard (Hg.): Die Bürokratie der Okkupation. Strukturen der Herrschaft und Verwaltung im besetzten Europa, Berlin 1998, S. 11-25, hier S. 21.

15 Manoschek, Walter: Partisanenkrieg und Genozid. Die Wehrmacht in Serbien 1941, in: Manoschek, Walter (Hg.): Die Wehrmacht im Rassenkrieg. Der Vernichtungskrieg hinter der Front, Wien 1996, S. 142-167, hier S. 143-145.

16 Bei Pavelićs Besuch im Führerhauptquartier 1942 beteuerte General Paulus, dass die Kroaten die besten Soldaten unter den deutschen „Hilfsvölkern“ seien. Kiszling: Die Kroaten, S. 188. Auch bei Slowaken oder Westukrainern „übersahen“ die Deutschen ihre slawische Abstammung. Vgl. Armstrong, John: Collaborationism in World War II: The Integral Nationalist Variant in Eastern Europe, in: The Journal of Modern History, 40 (1968) 3, S. 396-410, hier S. 403. 
te jedoch stets gewahrt bleiben. ${ }^{17}$ Das Reich war somit im Vorfeld des Zweiten Weltkrieges an der Erhaltung des jugoslawischen Staates interessiert. Daher scheiterten in dieser Zeit auch alle Versuche kroatischer Politiker, Hilfe für ihre separatistische Politik zu bekommen. So erklärte auch Hitler Pavelić bei ihrem ersten Zusammentreffen im Sommer 1941, dass er nicht vorgehabt habe, Jugoslawien zu zerstören und „zu einem ungewollten Werkzeug der Befreiung Kroatiens" wurde. ${ }^{18}$

Die feste wirtschaftliche Bindung an Südosteuropa sollte das deutsche Streben nach Autarkie unterstützen. In Übereinstimmung mit diesem Ziel wurde die Wirtschaft der südosteuropäischen Länder schon vor dem Krieg an Deutschland gebunden, indem im gesamten Raum ein Netz bilateraler Verträge aufgebaut wurde. Das Reich war bereit, für Rohstoffe und Lebensmittel deutlich höhere Preise als auf dem Weltmarkt zu bezahlen und lieferte seinerseits Fertigprodukte an die südosteuropäischen Länder. Auf diese Weise wurden diese an die Wirtschaft des Reiches gebunden und zu seinem „Ergänzungswirtschaftsraum“. ${ }^{19}$ Südosteuropa sollte das für die Kriegsbevorratung fehlende Brot- und Futtergetreide sowie den Großteil des deutschen Fleischbedarfs decken. Zudem verfügten diese Staaten über Rohstoffe, welche die deutsche Rüstungswirtschaft dringend benötigte, namentlich Bauxit, Chrom-, Antimon- oder Kupfererze. Zudem gab es in Rumänien und Ungarn Rohölvorkommen, deren Förderung nach An-

17 Abgesehen von Hitlers Beteuerungen gegenüber Mussolini, dass er im NDH nur wirtschaftliche und keine territorialen oder politischen Interessen verfolge, äußerte er 1940 bei den im Vorfeld des Zweiten Wiener Schiedsspruchs geführten Gesprächen ähnliche Ansichten bezüglich des gesamten Balkanraums, auch gegenüber dem rumänischen Präsidenten Ion Gigurtu sowie dem bulgarischen Ministerpräsidenten Bogdan Filov. Demnach war Deutschland an der Wirtschaft aller südosteuropäischen Länder interessiert, da es sie „zu seinem Wirtschaftsraum zugehörig betrachte“. Hillgruber, Andreas (Hg.): Staatsmänner und Diplomaten bei Hitler. Vertrauliche Aufzeichnungen über Unterredungen mit Vertretern des Auslandes 1939-1941, Bd. 1, Frankfurt/Main 1967, S. 172-175, $181 \mathrm{f}$.

18 Vgl. Aufzeichnung über die Unterredung Hitlers mit Pavelić, 9.6.1941, abgedr. i. ADAP, D, XII/2, Nr. 503, S. 657 f. Siehe auch Wuescht, Johann: Jugoslawien und das Dritte Reich. Eine dokumentierte Geschichte der deutsch-jugoslawischen Beziehungen von 1933 bis 1945, Stuttgart 1969, S. 183-190.

19 Schlarp, Karl-Heinz: Ausbeutung der Kleinen: Serbien in der deutschen Kriegswirtschaft 1941-1944, in: Bähr, Johannes/Banken, Ralf (Hg.): Das Europa des „Dritten Reichs“. Recht, Wirtschaft, Besatzung, Frankfurt am Main 2005, S. 187-215, hier S. 187-190. Beispielsweise gingen im Jahr 1938 50\% der jugoslawischen Ausfuhren nach Deutschland mit Österreich und dem Protektorat Böhmen-Mähren, während 49,9\% der Einfuhren aus diesem Raum stammten. Im Vergleich hierzu machte der wirtschaftliche Verkehr mit Großbritannien $10 \%$ und der mit Frankreich ca. $2 \%$ aus. Ein ähnliches Bild ergab sich auch für Ungarn, Rumänien, Bulgarien und Griechenland. Für genaue Zahlen vgl. Ristović: Nemački novi poredak, S. 16 f. 
sicht der deutschen Fachleute erheblich gesteigert werden konnte. ${ }^{20}$ Während des Krieges sollten die Länder Südosteuropas die ihnen zugedachte Rolle eines wichtigen Rohstofflieferanten weiter spielen. Dafür waren in den Jahren 193941 zahlreiche Studien angefertigt worden, die der Frage nachgingen, wie viele Rohstoffe Südosteuropa im Kriegsfall liefern könne. Durch die Besetzung westeuropäischer Länder und den Zugang zu deren Wirtschaftsräumen wurde die Bedeutung Südosteuropas jedoch relativiert. In den von deutschen Truppen besetzten Gebieten sollte die Wehrmacht trotzdem in erster Linie für eine reibungslose Förderung der Rohstoffe sorgen, indem sie das Gebiet sicherte und somit eine koordinierte Produktion ermöglichte. ${ }^{21}$ Wenn Deutschlands Vorstellungen jedoch nicht erfüllt wurden, indem, wie beispielsweise in Serbien, Aufstände gegen die deutsche Besatzung ausbrachen, kamen die rassistischen Vorstellungen der Nationalsozialisten sehr deutlich zu Tage und bestimmten seine brutale Aufständischenbekämpfung mit. ${ }^{22}$ Auch die Bevölkerung des verbündeten Unabhängigen Staates Kroatien wurde durch eine rassistische Brille gesehen und entsprechend hierarchisiert.

Klaus Olshausen hat überzeugend argumentiert, dass die Zerschlagung Jugoslawiens nur im Zusammenhang mit den Vorbereitungen des Unternehmens „Barbarossa“ erklärt werden kann..$^{23}$ Der Feldzug gegen Griechenland war schon in Vorbereitung und sollte von Bulgarien aus erfolgen, als Hitler nach dem Putsch in Belgrad die Entscheidung traf, Jugoslawien anzugreifen. Auch wenn seine Verachtung für die Serben dabei eine Rolle gespielt haben mag und die Entscheidung sehr spontan fiel, so dürfen Hitlers politisch-militärische Überlegungen nicht übersehen werden. Immerhin hatte der Putsch in Belgrad nicht nur die Regierung gestürzt, sondern auch den zwei Tage zuvor unterzeichneten Beitritt zum Dreimächtepakt rückgängig gemacht. Solange die jugoslawische Position unklar war, konnte nicht ausgeschlossen werden, dass England auf dem Balkan Fuß fassen würde, was wiederum die Durchführung der Operation „Barbarossa“ in Gefahr gebracht hätte. ${ }^{24}$

20 Rausch, Josef: Widerstand und Kollaboration in Jugoslawien 1941-1945 im Kontext von Jugoslawismus und partikulären Nationalismen, in: Suppan, Arnold/Lukan, Walter (Hg.): Nationalitäten und Identitäten in Ostmittel-Europa. Festschrift aus Anlass des 70. Geburtstages von Richard Georg Plaschka, Wien 1995, S. 195-219, hier S. 196; Das Deutsche Reich und der Zweite Weltkrieg, Bd. 1, S. 339 f.; 355.

21 Sundhaussen: Wirtschaftsgeschichte, S. 36-50; Das Deutsche Reich und der Zweite Weltkrieg, Bd. 1, S. 368.

22 Manoschek: Partisanenkrieg und Genozid, S. 142-167.

23 Olshausen: Zwischenspiel, S. 54 f. Dieser Meinung schließt sich auch Sundhaussen an. Sundhaussen: Okkupation, Kollaboration, Widerstand, S. 350.

24 Olshausen: Zwischenspiel, S. 50, $54 \mathrm{f}$. 
Die ökonomische und politische Abhängigkeit von Deutschland, die für die meisten Länder im Betritt zum Dreimächtepakt endete, hatte zunächst den Anschein einer Einigung Südosteuropas gebracht. Doch der Schein trog. Länder, die von den Pariser Vorortverträgen benachteiligt worden waren, stellten revisionistische Forderungen an diejenigen, die von den selbigen profitiert hatten. Unter dem „Achsenschirm“ kam es zur Öffnung und Internationalisierung aller nationalen Fragen. Daraus ergab sich eine Neuordnung dieses Raums, die sich nicht ,auf der Basis eines in sich geschlossenen, langfristig konzipierten Entwurfs“ vollzog. Stattdessen schuf Hitler ein Flickwerk unterschiedlicher besetzter oder scheinsouveräner Gebiete, die starke Interaktion zwischen den Besatzungsmächten sowie zwischen diesen und den einheimischen Machtträgern erforderten, die sich bald jeder Kontrolle entziehen sollten. ${ }^{25}$ Seine Politik der (Teil-)Befriedung italienischer, bulgarischer, ungarischer und kroatischer Territorialforderungen bei der Zerschlagung Jugoslawiens und Griechenlands zielte darauf ab, dass sich niemand mit seinem Nachbarn vertragen sollte, sodass es nicht zu einer Koalitionsbildung zum Schaden des Deutschen Reiches kommen konnte. Doch genau diese Divide-et-impera-Politik hinderte Hitler an der Erfüllung seiner beiden wichtigsten Ziele, nämlich die Befriedung des Raumes und seine ökonomische Ausbeutung. Das Reich musste erhebliche Kräfte aufwenden, um die geschaffene Pattsituation aufrecht $\mathrm{zu}$ erhalten. Im Krieg wurde der Südosten kaum der Rolle gerecht, die ihm das Reich zugeteilt hatte, nämlich der Erfüllung deutscher politischer, militärischer und ökonomischer Forderungen. ${ }^{26}$

Eine weitere wichtige Komponente der deutschen Außenpolitik in Südosteuropa war die Wahrung des guten Verhältnisses zu Italien, dem wichtigsten Verbündeten des Reichs. Dies war aber gerade dort besonders schwer, da Hitler und Mussolini zum Teil unterschiedliche Interessen verfolgten, wie die Beispiele Griechenlands und Jugoslawiens zeigen. Um seine eigene Stellung in Südosteuropa zu stärken, stellte Hitler Mussolini manchmal vor vollendete Tatsachen. So überging er Mussolini bei der Entscheidung, im Herbst 1940 eine deutsche Militärmission in Rumänien zu installieren. ${ }^{27}$ Auch alle Abgrenzungsversuche der Interessenssphären blieben vor dem Krieg noch sehr vage. Das Deutsche Reich erkannte schließlich die italienischen Ansprüche auf den Balkan als sei-

25 Ristović: Nemački novi poredak, S. 82; Olshausen: Zwischenspiel, S. 308; Sundhaussen: Improvisierte Ausbeutung, S. 59.

26 Sundhaussen: Okkupation, Kollaboration und Widerstand, S. 552; Ristović: Nemački novi poredak, S. $90 \mathrm{f}$.

27 Schreiber, Gerhard/Stegemann, Bernd/Vogel, Detlef: Der Mittelmeerraum und Südosteuropa. Von der „non belligeranza“ Italiens bis zum Kriegseintritt der Vereinigten Staaten, Stuttgart 1984, S. 418. 
nen spazio vitale grundsätzlich an, auch wenn es insbesondere hinsichtlich Jugoslawiens große wirtschaftliche und verkehrspolitische Vorbehalte hegte. ${ }^{28} \mathrm{Im}$ Unabhängigen Staat Kroatien mündeten die Abgrenzungsbemühungen in der wenig praktikablen Lösung, den ganzen Staat dem italienischen spazio vitale zuzurechnen, während das Reich sich darauf beschränken wollte, die wirtschaftlichen Ressourcen auszubeuten. ${ }^{29}$ Die höchsten Stellen in Deutschland wiederholten dies gebetsartig, doch verhielten sich insbesondere die deutschen Vertreter in Kroatien, wie noch gezeigt werden soll, häufig anders.

Schließlich spielte der Rassismus auch im NDH eine Rolle. Er stellte nicht die Triebfeder deutschen Handelns bei der territorialen Neugestaltung des jugoslawischen Raumes dar, wenn man vom nördlichen Teil Sloweniens absieht, das aufgrund rassischer Überlegungen an das Reich angeschlossen werden sollte. Doch bestimmte der Rassismus so entscheidend das nationalsozialistische Denken und Handeln, dass er zwangsläufig Auswirkungen auf alle Facetten der Politik hatte, auch wenn im NDH keine Absicht zur Germanisierung des Gebietes wie im östlichen Europa bestand. Für Serbien hat Walter Manoschek die Implikationen des Rassismus gegenüber den Serben bei der Niederschlagung des Aufstands aufgezeigt. ${ }^{30}$ Im Unabhängigen Staat Kroatien spielte der Rassismus eine maßgebliche Rolle bei der Verfolgung und Ermordung der kroatischen Juden und Roma. Darüber hinaus bestimmten auch im NDH rassistisch konnotierte Ressentiments gegenüber Serben die schlechte Behandlung dieser Bevölkerungsgruppe mit. Rassistische Vorurteile führten zudem zu einer sehr ambivalenten Wahrnehmung der muslimischen Bevölkerung. Der Umstand, dass südosteuropäische Völker auf der nationalsozialistischen rassischen Skala weit unten standen gepaart mit der geringen Bedeutung Südosteuropas für Deutschland führte schließlich dazu, dass das nationalsozialistische Deutschland dort eine Spur der Verwüstung hinterließ, die stark an die in Osteuropa

28 Mitrović, Andrej: Treći Rajh i italijanska privredna konkurencija u Jugoslaviji na početku drugog svetskog rata (1. septembar 1939 - 6. april 1941), in: Otisak iz zbornika filozofskog fakulteta, Bd. XIV/1, Belgrad 1979, S. 407-420. Das wird aus dem Bericht Ulrich von Hassels zum Ausgleich der deutschen und italienischen Wirtschaftsinteressen sehr deutlich. Hassel, Ulrich von: Südosteuropa. Bemerkungen zum Ausgleich der deutschen und italienischen Wirtschaftsinteressen. Sondergutachten des Botschafters z. V. U. von Hassel, Vorstandsmitglied des Mitteleuropäischen Wirtschaftstages. In italienischer Übersetzung ist das Dokument abgedruckt in: Collotti, Enzo/Sala, Teodoro (Hg.): Le potenze dell'Asse e la Jugoslavia. Saggi e documenti 1941/1943, Mailand 1974, S. 94-123.

29 Wie wichtig die ökonomischen Überlegungen für das Reich waren, wird auch aus einem italienischen Bericht deutlich, wonach die deutschen Garnisonen sich nur dort befanden, wo wichtige Industrien oder Minen zu verteidigen waren. ASMAE, GAB-AP 1923-1943, b. 1507, Presidi tedeschi nella Croazia, 9.3.1942.

30 Manoschek: Partisanenkrieg und Genozid, S. 142-167. 
erinnert. Es brauchte nicht zwangsläufig einer geplanten Vernichtungspolitik, um die gesamte Wucht der deutschen Zerstörung in Gang zu setzen. Manchmal reichten weit banalere Gründe, wie der Wunsch, ein unbedeutendes Gebiet „zu befrieden“, und die Tatsache, dass es sich um eine „rassisch minderwertige“ Bevölkerung handelte. ${ }^{31}$

\subsection{Die italienische imperiale Vision und die Balkanpolitik in der Zwischenkriegszeit}

Ähnlich wie die Nationalsozialisten träumten auch die Faschisten davon, ein eigenes, faschistisches Imperium $\mathrm{zu}$ errichten, einen eigenen spazio vitale $\mathrm{zu}$ schaffen. Auch wenn dieser italienische Ausdruck die wörtliche Übersetzung des deutschen Wortes „Lebensraum“ ist, so unterschied sich die italienische Vorstellung deutlich von ihrem deutschen Pendant. ${ }^{32}$ Emilio Gentile bringt die faschistische Idee des Imperiums auf den Punkt, wenn er ausführt:

Für den Faschismus deckte sich die Idee des Imperiums nicht mit Imperialismus, sie identifizierte sich weder mit Kolonialismus noch mit der Eroberung neuer Territorien, sondern sie äußerte in erster Linie die Absicht, eine neue Zivilisation zu erschaffen, welche im zwanzigsten Jahrhundert zu einem universellen Modell emporsteigen sollte, wie die römische Zivilisation in der Antike. ${ }^{33}$

Bereits in den 1920er Jahren befassten sich die faschistischen Intellektuellen mit der Expansion, die sowohl als ein Recht als auch eine Pflicht angesehen wurde. Nach Mussolini sollte das 20. Jahrhundert dasjenige des universellen Faschismus sein und eine neue Zivilisation begründen. ${ }^{34}$ Dabei sollte die faschistische, auf der moralischen, kulturellen und ökonomischen Überlegenheit aufbauende Version des Imperialismus anders sein als in „klassischen“ Imperien, die rein auf die Vergrößerung des Territoriums abzielten. Darüber hinaus würde der italienische Korporativismus ${ }^{35}$ ein weiterer Garant für die Andersartigkeit

31 Im Gegensatz zu Südosteuropa gab es in west- und nordeuropäischen Ländern unterschiedlich ausgeprägte Versuche, die „rassich wertvolle“ germanische Bevölkerung „einzubinden“. Vgl. Fleischer: Nationalsozialistische Besatzungsherrschaft im Vergleich, S. $294 \mathrm{f}$.

32 Um dies auch sprachlich zum Ausdruck zu bringen, wird im Text die italienische Vorstellung vom Lebensraum stets mit spazio vitale bezeichnet.

33 Gentile, Emilio: Fascismo di pietra, Roma ${ }^{3} 2008$, S. $198 \mathrm{f}$.

34 Knox, MacGregor: Conquest, Foreign and Domestic, in Fascist Italy and Nazi Germany, in: The Journal of Modern History, 56 (1984) 1, S. 1-57, hier S. 11.

35 Der Korporativismus war das von den Faschisten entwickelte sozioökonomische Gegenmodell zu Kapitalismus und Kollektivismus, um die soziale Frage zu lösen und die Klassenkon- 
der italienischen Expansion sein. Schließlich sollte die Kolonisierung von der italienischen Fähigkeit, „sich beliebt zu machen“, begleitet werden. ${ }^{36}$ Diese Ideen kulminierten schließlich in den 1930er und 1940er Jahren in Versuchen, das Konzept des Nationalstaates durch das Konzept der imperialen Gemeinschaft, welche die Trägerin einer neuen Zivilisation sein sollte, zu ersetzen. ${ }^{37}$

Journalisten und Wissenschaftler des Regimes schrieben in Folge Tausende von Seiten zu diesem Thema und machten sich daran zu klären, welcher Natur das Imperium sein sollte, das sie anstrebten. Auch wenn eine klare Definition nie gegeben wurde, hatte die vage Vorstellung vom Imperium, die sich im Laufe des ventennio, also der zwanzigjährigen Herrschaft der Faschisten, zudem veränderte, stets eine materielle und eine geistige Implikation. Um eine Ausdehnung des Imperiums speziell auf den Balkan zu begründen, konnten jedoch ökonomische, militärische und ideologische Motive nicht zu einem kohärenten Bündel zusammengeschnürt werden. Stattdessen folgten die Schriften den politischen Hochs und Tiefs in den jeweiligen bilateralen Beziehungen durch die Jahrzehnte bis zum Krieg. ${ }^{38}$ Trotz aller Unschärfe, welche die italienischen imperialen Vorstellungen prägte, kann man einige Vorstellungen identifizieren, die untrennbar damit verbunden waren. Diese sind durch die Schlageworte Romanità, Zivilisierungsmission, spazio vitale und Rassismus gekennzeichnet.

Im Konzept des faschistischen Imperiums spielte der Mythos der Romanità eine wichtige Rolle. In der Forschung wird dieser heute nicht mehr nur als bloße Propaganda gedeutet, sondern als der Grundpfeiler der ideologischen und symbolischen Welt des Faschismus von den ersten Tagen der Bewegung bis zu ihrem Ende. Er war im ventennio omnipräsent. ${ }^{39}$ Die Romanità war ein dehnba-

flikte zu überwinden. Schembs, Katharina: Korporativismus, Arbeit und Propaganda im faschistischen Italien (1922-1945), in: Buggeln, Marc/Wildt, Michael (Hg.): Arbeit im Nationalsozialismus, München 2014, S. 141-164, hier S. 142.

36 Roberts: Myth, Style, Substance, S. 31; Zunino, Pier Giorgio: L'ideologia del fascismo. Miti, credenze e valori nella stabilizzazione del regime, Bologna 1985, S. 359; Bianchini, Stefano: L'idea fascista dell'impero nell'area danubiano-balcanica, in: Di Nolfo, Ennio/Rainero, Romain H. (Hg.): L'Italia e la politica di potenza in Europa, Bd. 1: 1938-40, Milano 1985, S. 173-186, hier S. 180 f.; Cerasi, Laura: Empires ancient and modern: strength, modernity and power in imperial ideology from the Liberal period to Fascism, in: Modern Italy 19 (2012) 4, S. 421-438, hier S. 426.

37 Gentile, Emilio: La nazione del fascismo, S. 90, 94. Siehe auch Gregor, James: Mussolini's intellectuals. Fascist social and political thought, Princeton/Oxford 2005, S. 178-184.

38 Casella, Francesco: L'imagine fascista dell'impero: Quale ruolo all'Adriatico?, in: Di Nolfo, Ennio/Rainero, Romain H. (Hg.): L’Italia e la politica di potenza in Europa, Bd. 1: 1938-40, Milano 1985, S. 187-203.

39 Zur ausführlichen Analyse der Romanità unter dem Faschismus siehe Nelis, Jan: From ancient to modern: The myth of romanità during the ventennio fascista. The written imprint of Mus- 
res ideologisches Konstrukt, das auf der Vorstellung von der Existenz eines ideologischen Erbes des antiken Rom aufbaute. Diese Vorstellung repräsentierte ein relativ kohärentes Ideenbündel, das nicht nur das faschistische totalitäre Konzept vom Staat unterstützte, sondern auch den faschistischen Imperialismus, der, mit einer zivilisatorischen Mission ausgestattet, darauf abzielte, die römischen „Tugenden“ in der Welt zu verbreiten. ${ }^{40}$

Die Romanità diente Mussolini während des ersten Weltkriegs zunächst der Disziplinierung der Italiener: Das antike Rom wurde zum Vorbild für die Konzepte von Diktatur, Disziplin und Hierarchie stilisiert, um die Italiener zu militarisieren und so den Sieg zu gewährleisten. Nachdem die Faschisten Anfang der 1920er Jahre zu einer Massenbewegung aufgestiegen waren, wurde das antike Rom, als die vermeintlich perfekte Gesellschaft, endgültig zu ihrem Symbol. Sie sahen sich selbst als die Avantgarde der Wiedergeburt des italienischen Volkes (stirpe), die einen neuen Staat kreieren wollte, welcher in den Italienern den imperialen Geist und die universelle römische Tradition erneuern sollte. ${ }^{41}$ Aufbauend auf dem römischen Erbe sollte das neue italienische Imperium ein Garant für universelle Gerechtigkeit sein.

Bestimmte Vorstellungen von Rom, die die Faschisten unter dem Begriff der Romanità zusammenfassten und die auch von den Wissenschaftlern, die sich mit der Antike beschäftigten, perpetuiert wurden, porträtierten die Römer als Philanthropen. Ihre imperialen Eroberungen hätten sie zum Schutz vor der Barbarei betrieben, um den Frieden nicht nur für die Eroberer, sondern auch für die Eroberten zu sichern. Gerechtigkeit (giustizia) und Zivilisierung (incivilmento) waren die Schlagwörter in zahlreichen zeitgenössischen Publikationen. ${ }^{42}$ Dieser einseitige Zugang zur römischen Zivilisation postulierte Recht, Ordnung und Gerechtigkeit als grundlegende Werte der Romanità und wurde in den

solini’s cult of the „Third Rome“, Brüssel/Rom 2011, S. 36, 40, 169-171; Stone, Marla: A flexible Rome: Fascism and the cult of romanità, in: Edwards, Catharine (Hg.): Roman Presences: Receptions of Rome in European Culture, 1789-1945, Cambridge/New York, 1999, S. 205-220, hier S. 205; Aramini, Donatello: The Myth of ,Christian Rome، and the Institute of Roman Studies: An Attempted Synthesis of Fascism and Catholicism, in: Journal of Contemporary History 50 (2015) 2, S. 188-214, hier S. 189. Siehe auch den Eintrag zur Romanità in De Grazia, Victoria/ Luzzatto, Sergio (Hg.): Dizionario del fascismo, Bd. 2, Turin 2003, S. 539-541.

40 Visser, Romke: Fascist Doctrine and the Cult of the Romanità, in: Journal of Contemporary History, 27 (1992) 1, S. 5-22, hier S. 17.

41 Gentile: Fascismo di pietra, S. 41-43; Burdett, Charles: Italian Fascism and utopia, in: History of the Human Sciences 16 (2003) 1, S. 93-108, hier S. 96.

42 So z. B. Romagnoli, Ettore: Pubilius Vergilius Maro, Rom 1931, S. 15. Bottai, Giuseppe: L'Italia di Augusto e l'Italia oggi, Rom 1937, S. 7 f., Pais, Giuseppe: Roma dall'antico al nuovo impero, Mailand 1938, S. 214 f. Ausführlich hierzu: Nelis: From ancient to modern, S. 69 f.; Cagnetta, Mariella: Antichisti e impero fascista, Bari 1979. 
1930er Jahren immer wichtiger. ${ }^{43}$ Insbesondere nachdem die Wiedererrichtung des Imperiums am 9. Mai 1935 verkündet worden war, wurde der Rückbezug auf die römische Geschichte, um die faschistische Politik zu legitimieren, eine weit verbreitete Mode. ${ }^{44}$ Zahlreiche Autoren sahen in der Schaffung eines Imperiums nicht nur ein Recht, sondern sogar eine Pflicht. Die Definition des Imperiums blieb dabei weiterhin vage und hing davon ab, wer zu welcher Zeit darüber schrieb. Aufbauend auf der Romanità hatten die Faschisten ein eigenes imperiales Konzept entwickelt, das beide von Jürgen Osterhammel beschriebenen Dimensionen einschloss: die horizontale Dimension der räumlichen Ausbreitung, wobei sich das Imperium an den Rändern durchaus inklusiv verhalten sollte, sowie die vertikale Dimension der Erhebung und Erhöhung. ${ }^{45}$ Hierbei spielte auch das Konzept der „Zivilisierungsmission“ eine große Rolle. Auf Krieg und Kampf sollten Frieden und Stabilität folgen. Ähnlich wie das Römische Reich würde das faschistische Italien nicht nur erobern, sondern auch zivilisieren. ${ }^{46}$ Das antike Rom diente somit als Legitimation und als Beispiel für das neue faschistische Imperium. In Mussolinis Worten:

Das faschistische Italien verwandelt, wie einst Rom, die eroberten Länder in seine Ebenbilder und dafür entsendet es seine besten Männer dorthin. [...] Seine Untertanen fordern nicht die Autonomie, sondern, mit Stolz, die italienische Staatsbürgerschaft. ${ }^{47}$

Das Regime ermunterte von Anfang an Produktion von Texten, welche die Einzigartigkeit des italienischen Imperialismus betonten sowie die italienischen

43 Giardina, Andrea/Vauchez, André: Il mito di Roma. Da Carlo Magno a Mussolini, Rom/Bari 2000, S. 215 f. Visser: Fascist Doctrine, S. 15, Gentile: Fascismo di pietra, S. 52.

44 Gentile: Fascismo di pietra, S. 206; Stone: Flexible Rome, S. 208-219.

45 Osterhammel, Jürgen: „The Great Work of Uplifting Mankind“. Zivilisierungsmissionen und Moderne, in: Barth, Boris/Osterhammel, Jürgen (Hg.): Zivilisierungsmissionen. Imperiale Weltverbesserungen seit dem 18. Jahrhundert, Konstanz 2005, S. 363-425, hier S. $363 \mathrm{f}$.

46 Nelis, Jan: Constructing Fascist Identity: Benito Mussolini and the Myth of Romanità, in: The Classical World, 100 (2007) 4, S. 391-415, hier S. 401; Nelis: From ancient to modern, S. 60; Nellis: Imperialismo, S. 8.

47 Il Popolo d'Italia, Nr. 136, 7.6.1935, XXII, abgedr. i. Susmel, Edoardo/Susmel, Duilio (Hg.): Opera Omnia di Benito Mussolini, Bd. 27: Dall'inaugurazione della Provincia di Littoria alla proclamazione dell'Impero (19 dicembre 1934 - 9 maggio 1936), Florenz 1959, S. 84. Die Realität sah freilich meistens ganz anders aus. Giorgio Rochat attestierte dem faschistischen Reich zwar diverse moderne Elemente, doch er bemängelte das Fehlen eines Programms für eine realistische Koexistenz mit der afrikanischen Lokalbevölkerung. Der Krieg in Äthiopien sei immer mit harten und wahllosen Repressionen geführt worden, ohne Versuche, die Bevölkerung jenseits der Askari-Truppen einzubeziehen. Rochat, Giorgio: La guerra italiana in Etiopia: modernità e limiti, in: Bottoni, Riccardo (Hg.): L'Impero fascista: Italia ed Etiopia, 1935-1941, S. 105-116, hier S. 113. 
Kolonien beschrieben und so propagandistisch auf die italienische Bevölkerung einwirkten. Hierunter fiel die weit verbreitete Reiseliteratur, die sich überwiegend mit dem Regime und seiner Ideologie identifizierte. Die Propagatoren des Imperiums in Italien betonten unterschiedliche zivilisatorische Leistungen in Afrika, wie z. B. den Bau von Straßen, Telefon- und Telegraphennetzen oder den Ausbau der Wasserversorgung durch die Truppen, die nach dem Krieg „friedliche Instrumente der Zivilisation“ werden sollten. Des Weiteren wurde die italienische „Großzügigkeit“ in Form von ärztlicher Versorgung der Bevölkerung erwähnt, auf die das faschistische Italien stolz sein könnte. Die Kolonisation sollte die kolonisierten Völker auf neue zivilisatorische Stufen bringen. Gleichzeitig wurde auch von der Unterdrückung des Widerstands gegen die italienische Herrschaft geschrieben, ohne dass die Autoren hier einen Gegensatz ausmachten. ${ }^{48}$ In solchen Texten spiegelte sich sowohl die Überzeugung des Zivilisators von seiner Überlegenheit, als auch die Erwartung an die zu Zivilisierenden (oder zumindest an einen Teil von ihnen), das Angebot anzunehmen und darüber hinaus Dankbarkeit zu zeigen. Das Konzept kennt kein Scheitern, keine Unwilligkeit der Besiegten, sich „zivilisieren“ zu lassen. ${ }^{49}$

Letzteres sollte - wie noch zu zeigen sein wird - die Italiener in Kroatien (und nicht nur dort) vor große Probleme stellen. Die Slawen jenseits der italienischen Grenze sollten die Rezipienten der italienischen Zivilisierungsmission werden. ${ }^{50}$ So sprach Bottai von Triest als dem „Zentrum der geistigen Ausstrahlung der Romanità in die benachbarten Gebiete jenseits der Grenze“. ${ }^{51}$ Doch die Bevölkerung in den annektierten und besetzten Gebieten wollte die italienische Führungsrolle sowie ihre „zivilisatorische Überlegenheit“ nicht akzeptieren. Ein solches Verhalten beschrieben die italienischen Besatzer vermeintlich folgerichtig als „Undankbarkeit“. 52

48 Lessona, Alessandro: Le colonie d'Italia, in: Dal regno all'impero 17 marzo 1861 - 9 maggio 1936 - XIV, hgg. v. Reale Accademia Nazionale dei Lincei, Rom 1937, S. 683-697, hier S. 695697; Burdett, Charles: Fictions and Narratives of Empire, in: A historical companion to postcolonial literatures: Continental Europe and its Empires, Edinburgh 2008, S. 281-283, hier S. 282. 49 Osterhammel: Zivilisierungsmissionen, S. 364 f., 371.

50 Sluga, Glenda: Identità nazionale italiana e fascismo: alieni, alogeni e assimilazione sul confine nord-orientale italiano, in: Cattaruzza, Marina (Hg.): Nazionalismi di frontiera: Identità contrapposte sull'Adriatico nord-orientale 1850-1950, Rubbettino, S. 171-202, hier S. 196.

51 Vinci, Anna: „Geopolitica“ e Balcani: L'esperienza di un gruppo di intellettuali in un ateneo di confine, in: Società e storia 13 (1990) 47, S. 87-127, hier S. 114.

52 Beispielsweise schalt der Präfekt der Provinz von Split am 26.9.1941 die Dalmatiner: „Wir geben Euch mehr Brot, als wir in Italien verteilen. Wir geben euch Fleisch und andere Nahrungsmittel, was in Italien selten ist. Euren Kindern geben wir Süßigkeiten und Milch [...] ihr wisst aber nicht, was Dankbarkeit ist, sondern ermordet Carabinieri.“ Zit. nach Barbarić, Juraj: 
Für die faschistische imperiale Vorstellung spielte weiterhin die Idee von der Nation als einer Willensgemeinschaft eine wichtige Rolle. Bereits vor dem Faschismus existierte die Ansicht, dass die italienische (höher stehende) Kultur andere in Italien lebende Minderheiten assimilieren könnte. Diese Auffassung vertraten zunächst auch die Faschisten. Doch spätestens mit dem Aufbau des Imperiums begann auch der Rassismus eine immer wichtigere Rolle $\mathrm{zu}$ spielen. Bis dahin versuchten sich die Faschisten im internationalen Rahmen vom nationalsozialistischen Rasseverständnis abzugrenzen. So war das letzte Treffen der Faschistischen Internationale 1935 der Kritik am Rassismus gewidmet. ${ }^{53}$ Auch im Inneren wurde die anthropologische Vielfalt der italienischen „Stämme“ gepriesen und die deutschen Rassengesetze abgelehnt. Nach dieser Anschauung führte die regionale Differenz der italienischen „Stämme“ dazu, dass die äußeren Unterschiede stets hinter die integrative Kraft des Geistes und der Geschichte traten. Bis 1938 wurden auch die Begriffe „stirpe“ und „razza“ mit wenigen Ausnahmen synonym verwendet. ${ }^{54}$

Das Jahr 1936 wird gemeinhin als der Wendepunkt der faschistischen Haltung zum Rassismus betrachtet. Während er vorher nur eine marginale Rolle gespielt hatte, stieg er nun auch im faschistischen Italien $\mathrm{zu}$ einem wichtigen ideologischen und politischen Element auf. Dieser äußerlich relativ abrupte Kurswechsel, auf den weder die italienische Gesellschaft noch die Faschisten vorbereitet waren, verlangt nach einer Erklärung. Viele Zeitgenossen und auch einige Historiker haben die Verabschiedung der Rassengesetze auf den deutschen Druck bzw. Mussolinis Willen zurückgeführt, alle potentiellen Widersprüche in der Politik der beiden Länder zu beseitigen. Diese These wird jedoch mittlerweile kaum noch vertreten. ${ }^{55}$ Stattdessen wird davon ausgegangen, dass diese Entwicklung eigenständig im Faschismus, der stets auch den Keim des Antisemitismus in sich trug, seit den 1920er Jahren gereift sei. Dazu beigetragen haben einige Entwicklungen in den 1930er Jahren, wie das allgemeine antisemitische Klima in Europa, die Haltung der italienischen Juden gegenüber den in Deutschland verfolgten Juden, die somit ihre Inkompatibilität mit dem italieni-

Talijanska politika u Dalmaciji 1941. godine (Institut za historiju radničkog pokreta Dalmacije), Split 1972, S. 148.

53 Ledeen, Michael: Universal fascism: the theory and practice of the Fascist International, 1928-1936, New York 1972, S. 114, 124.

54 Maiocchi, Roberto: Scienza italiana e razzismo fascista, Florenz 1999, S. 57, 78 f., 139.

55 Vgl. D’Onofrio, Andrea: I rapporti tra Italia e Germania e il razzismo fascista, in: Flores, Marcello [et.al.] (Hg.): Storia della Shoah in Italia. Vicende, memorie, rappresentazioni, Bd. 1: Le premesse, le persecuzioni, lo sterminio, Turin 2010, S. 221-255, hier S. 245-247; Sarfatti, Michele: La legislazione antiebraica 1938-1943, in: Flores (Hg.): Storia della Shoah in Italia, Bd. 1, S. 283-302, hier S. 284-286. 
schen Nationalismus und Faschismus gezeigt hätten oder die Errichtung des italienischen Imperiums. ${ }^{56}$ Insbesondere der letzte Punkt verdient etwas mehr Aufmerksamkeit. In Afrika konnten die Faschisten aufgrund der äußerlichen Merkmale angeblich biologischer Rassen leichter ein Rassenbewusstsein kreieren, das in Rassismus und Apartheid-ähnlichen Zuständen mündete. Die Vorgänge in den Kolonien wirkten nach Meinung der meisten Historiker rückkoppelnd auf das Mutterland, wo nach Victoria De Grazia die Italiener lernen sollten, „wie sich die legitimen Bürger ihres Staates von jenen unterschieden, die nur bloße Untertanen waren und nur entsprechend den Rechten und Pflichten regiert wurden, die ihnen aufgrund ihrer minderwertigen Rasse zustanden““.57

Das Manifesto della razza vom Sommer 1938 und die zwischen September und November desselben Jahres verkündeten Rassengesetze ${ }^{58}$ schafften, ähnlich wie die Nürnberger Gesetze, eine Abgrenzung der Mitglieder der italienischen Nation von ihren bloßen Untertanen: die „Arier“ wurden von „Nicht-Ariern“ getrennt. Damit verfolgte Mussolini in erster Linie das Ziel, die Italiener zu einen und ihr rassisches Bewusstsein zu schärfen. Er entschied sich für die Ausgrenzung der Juden, nachdem er die einigende Wirkung des NS-Antisemitismus beobachtet hatte. Sie sollten zwar nicht verfolgt, aber diskriminiert werden. Das bis dahin in Italien verbreitete Rassenkonzept wurde also um die biologische Komponente erweitert. ${ }^{59}$

Ihrer Definition der Slawen legten die Faschisten hingegen vor und nach 1938 keine rassischen, sondern kulturelle Gesichtspunkte zugrunde. Sie konn-

56 Sarfatti: La legislazione antiebraica, S. $285 \mathrm{f}$.

57 Pergher, Roberta: Borderlines in the Borderlands: Defining difference through history, „race“, and citizenship in fashist Italy, EUI Working Paper MWP, San Domenico di Fiesole 2009, S. 21. De Grazia, Vittoria: Die Radikalisierung der Bevölkerungspolitik im faschistischen Italien: Mussolinis „Rassenstaat“, in: Geschichte und Gesellschaft, 26 (2000) 2, S. 219-254, hier S. 246. Ähnlich auch Collotti, Enzo: Il fascismo e gli ebrei. Le leggi razziali in Italia, Rom/Bari 2003, S. 39; Kallis: Fascist Ideology, S. 45.

58 Ausführlicher zu den einzelnen Gesetzen: Moos, Carlo: Der späte italienische Faschismus und die Juden. Hintergründe und Folgen einer rassenpolitischen Wende, <http://www.europa. clio-online.de/2008/Article=286> (20.12.2018), S. 1-13, hier S. $1 \mathrm{f}$.

59 Gilette, Aaron: Guido Landra and the Office of Racial Studies in Fascist Italy, in: Holocaust and Genocide Studies, 16 (2002) 3, S. 357-375, hier S. 358 f.; De Grazia: Radikalisierung, S. 246248; Sarfatti, Michele: La Shoah in Italia. La persecuzione degli ebrei sotto il fascismo, Turin 2005, S. 78-81; Maiocchi: Scienza italiana, S. 241. Siehe zudem den kürzlich erschienenen, erhellenden Aufsatz von Patrick Bernhard, der die Unterschiede zwischen dem deutschen und dem italienischen Rassismus auf das diskursive Aushandeln dessen, was „Rasse“ bedeuten sollte, zwischen mehreren Individuen und Gruppen in beiden Staaten sowie auch den Versuch, in beiden Staaten eigene Identitäten zu schaffen, zurückführt. Bernhard, Patrick: „The Great Divide? Notions of Racism in Fascist Italy and Nazi Germany: New Answers to an Old Problem“ in: Journal of Modern Italian Studies 24 (2019) 1, S. 97-114. 
ten durch Assimilierung zu Italienern werden. Die Deutschen im Norden und die Slawen im Nordosten des Landes, die sich nach dem Ende des Ersten Weltkriegs in Italien wiederfanden, sowie das Land selbst sollten italianisiert werden, indem ihre Sprachen benachteiligt, Orts- und Personennamen italianisiert und Italiener in ihren Wohngebieten angesiedelt wurden. In Venezia Giulia, wo der größte „Erfolg“ zu verzeichnen war, wurden ab 1928 auch die Vornamen italianisiert. ${ }^{60}$ Diese Politik der De-Nationalisierung, die einige Historiker als „,kulturellen Genozid“ werten, war somit ein Aspekt des totalitären Ansatzes des Faschismus. ${ }^{61}$

Anderes war vorgesehen für den spazio vitale, also Italiens imperialen Raum. Als solcher wurde zunächst der Mittelmeerraum, il mediterraneo oder mare nostrum, bezeichnet, wobei es unterschiedliche Ansichten gab, welche Gebiete dazu gehören sollten. In seiner ultima ratio sollte Italien aus seinem „Gefängnis“ im Mittelmeer ausbrechen und sich den Weg zum Ozean frei machen. ${ }^{62}$ In Europa sollte das italienische Imperium französische, jugoslawische, albanische und griechische Gebiete umfassen, wobei die Ausdehnung sowie ihre Stellung im Imperium variierten. ${ }^{63}$ Dalmatien, als terra irredenta ${ }^{64}$, sollte an Italien angeschlossen werden. Wie weit sich der spazio vitale hinter Dalmatien ausstrecken oder wie die restlichen Gebiete organisiert werden sollten, blieb bis zum Ausbruch des Krieges gegen Jugoslawien unklar. Die italienische Vorherrschaft im Mittelmeerraum blieb aber das stets verfolgte Ziel.

Um diese Ideen zu verbreiten entstanden seit dem Beginn der 1930er Jahre verschiedene Initiativen und Institute, die vor allem die Archäologie, die Kolonial-, Afrika- sowie Orientstudien im faschistischen Sinn beeinflussten. ${ }^{65}$ Für die Legitimierung der Expansion in Richtung Balkan war insbesondere das 1932

60 Caccamo, Giulia/Di Michele, Andrea/Pupo, Raoul: La vittoria senza pace: le occupazioni militari italiane alla fine della Grande Guerra, Rom 2014; Sluga: Identità nazionale, S. 180, 183 f., 195; Klein, Gabriela: La politica linguistica del fascismo, Bologna 1986, S. 75-77, $94-$ 110. Zur Situation in Venezia Giulia siehe insbesondere Hametz, Maura: Naming Italians in the borderland, 1926-1943, in: Journal of Modern Italian Studies, 15 (2010) 3, S. 410-430 und Cattaruzza, Marina: L'Italia e il confine orientale 1866-2006, Bologna 2007, S. 168-188. 61 Cattaruzza: L'Italia e il confine orientale, S. 186.

62 Es blieb jedoch unklar, ob der Ausbruch in Richtung Atlantik oder indischer Ozean erfolgen sollte. Kallis: Fascist Ideology, S. 122.

63 Rodogno, Davide: Sogni di conquista, S. 115.

64 Terra irredenta bedeutet wörtlich das (noch) unbefreite Land und bezog sich nach der italienischen Einigung 1861 auf die als italienisch angesehenen Gebiete außerhalb der italienischen Grenzen.

65 Eine Idee, die in den 1930er Jahren verbreitet wurde, war die des korporativen Kolonialismus. Pasetti, Matteo: Un ,Colonialismo Corporativo‘? L'Imperialismo Fascista Tra Progetti e Realtà, in: Storicamente, 12 (2016) 3, S. 1-30. 
gegründete Institut für adriatische Studien in Venedig zuständig. Hier baute man vor allem auf dem venezianischen Erbe an der östlichen Adria auf, das lokal eine ähnliche Funktion wie der Mythos von Rom hatte. ${ }^{66}$

Obwohl vor dem Krieg keine Einigung darüber erfolgt war, wie nun ganz konkret das Imperium auszusehen hatte, stellten während des Krieges die faschistischen Ideologen in der zeitgenössischen Presse heraus, dass die Bildung des faschistischen Imperiums und des italienischen spazio vitale in den besetzten und annektierten Gebieten im Einklang mit den jahrelang propagierten Ansichten voran schritt. Dies illustriert folgender kurzer Pressespiegel. Im Artikel „Contributo dell'Italia fascista al ,Nuovo ordine““ von 1941 argumentierte Giuseppe Bottai, dass an der von Italien in den besetzten Gebieten bisher verfolgten Politik auch das italienische Konzept der europäischen Ordnung sichtbar werden würde. Er betonte, dass Italien die besiegten Völker nicht erniedrigen oder versklaven wolle, sondern ihre weitere Erhebung und Zivilisierung verfolge. Der Faschismus würde diese Völker durch die kulturelle und wirtschaftliche Überlegenheit Italiens anziehen. ${ }^{67}$ Sowohl mit Blick auf die afrikanischen Kolonien als auch auf die europäischen Eroberungen machte Bottai im Anschluss die Vorzüge der italienischen Herrschaft deutlich. Italien habe den Völkern wirtschaftliche und politische Entwicklung gebracht, ohne die lokalen Bräuche zu missachten, so z. B. die Scharia beibehalten. ${ }^{68}$ Schließlich würden die Proklamationen des Duce für die besetzten Gebiete den Keim der zukünftigen mediterranen Ordnung bilden. Dies alles zeige, wie Italien bei der Implementierung einer neuen Ordnung nicht nur mit Waffen, nicht nur mit Gesetzen und Institutionen, sondern auch - was noch mehr zähle - mit seiner eigenen ordnenden Einstellung seinen Beitrag leiste. ${ }^{69}$ Ähnlich verlangte Camillo Pellizzi, der Präsident des Istituto Nazionale di Cultura Fascista: „Ein konkretes, universelles Prinzipmuss auf den Spitzen unserer Bajonetten sein, ansonsten ist sogar der Sieg für uns nutzlos und schädlich.“70

Noch konkreter sprach ein Artikel über die Besatzung in Griechenland die tatsächlich verfolgte Politik an. Darin hieß es, dass ein kurzer Besuch Mussolinis in Athen den Griechen gezeigt habe, dass Italien „den griechischen Geist

66 Paladini, Filippo Maria: Velleità e capitolazione della propaganda talassocratica veneziana (1935-1945), in: Isnenghi, Mario/Fincardi, Marco (Hg.): L'Italia chiamò. Memoria militare e civile di una regione, 2002, S. 147-172.

67 Bottai, Giuseppe: Contributo dell'Italia fascista al „Nuovo ordine“, in: Civiltà fascista, Nr. 12, Jg. XIX (1941), S. 6-26, hier S. 12-16.

68 Bottai: Contributo dell'Italia fascista al „Nuovo ordine“, S. 18-21.

69 Bottai: Contributo dell'Italia fascista al „Nuovo ordine“, S. 24.

70 Pellizzi, Camillo: Italia e Germania. Problemi del nuovo ordine, in: Civiltà fascista, Nr. 1-2 (November-Dezember) 1941, S. 26-31, hier S. 31.“/p> 
nicht ersticken, sondern intelligent fördern und im italienischen mediterranen Raum wirken lassen“ würde. Dazu gehöre, die griechische staatliche Integrität zu respektieren (abgesehen von den ionischen Inseln und den Kykladen, die jedoch beide griechische Verwaltung beibehalten hätten). Ferner betont der Autor das „humane“ Benehmen der italienischen Besatzungstruppen sowie das korrekte italienische Verhalten bezüglich der lokalen wirtschaftlichen Produktion schließlich habe Italien sogar etliche Tonnen Mehl nach Griechenland eingeführt. Dies alles tue Italien, weil Griechenland in einem zukünftigen italienischen mediterranen Raum eine erstrangige Stellung und Funktion innehaben würde:

Es ist genau diese sehr große und intelligente Zukunftsvision, die als Inspiration für das italienische Verhalten in Griechenland dient, welches darauf abzielt, die spirituellen und materiellen Interessen des hellenischen Volkes zu beschützen, um in ihm einen hingebungsvollen und überzeugten Mitarbeiter der zukünftigen europäischen Ordnung zu haben. ${ }^{71}$

Ähnlich waren auch die Überlegungen in zwei Berichten zur Stellung Albaniens innerhalb der imperialen Gemeinschaft, die beide durch einen Artikel respektive eine Rede des Außenministers Ciano zu diesem Thema motiviert worden waren. Darin wurde wiederholt, dass sich Italien an den Gesetzen des faschistischen imperialen Konzepts orientiert und der albanischen Regierung weitgehende Freiheiten belassen habe und nur dort korrigierend eingreife, wo diese entgegen den Interessen der imperialen Gemeinschaft handelte. ${ }^{72}$ Der Albanische Fall sei dabei als praktisches Experiment zu sehen, in dem die Prinzipien des Imperiums und der „Führung“ der Völker in einem bestimmten spazio vitale erprobt worden seien; Ziel sei es auch gewesen, einige besondere Eigenschaften und nationale Charakteristika der an Italien gebundenen Völker intakt zu erhalten. Nach diesem Prinzip sei schließlich auch in Montenegro und - in einer anderen Form - in Kroatien verfahren worden. ${ }^{73}$

Einer ähnlichen Sprache bedienten sich auch die höchsten Stellen im Staat. So beanspruchte Mussolini, als es um die Neuordnung der jugoslawischen Gebiete ging, folgendes Prinzip: „Wir wollen assoziieren, nicht inkorporieren.“74 Dabei kam Albanien, das stets als das beste Modell der zukünftigen untergebenen, aber kooperativen Beziehung zwischen dem Hegemon und der assoziierten

71 Codro, Regdo: „La giovane Grecia nello spazio mediterraneo“, in: Critica fascista, Jg. XX (1942), Nr. 23, S. $304 \mathrm{f}$.

72 L'Albania nella comunità imperiale, in: Critica fascista, Jg. XX (1942), Nr. 6, S. 90 f.

73 Airoldi, Aldo: Politica estera italiana, in: Critica fascista, Jg. XX (1942), Nr. 16, S. 220.

74 Eintrag vom 14.5.1941, nach der Unterzeichnung der Römischen Protokolle, in: Bottai, Giuseppe: Vent'anni e un giorno, Mailand 1977, S. 203. 
Gemeinschaft im italienischen spazio vitale dargestellt wurde, die Rolle des Vorbilds zu. Der Zeitpunkt relativiert Mussolinis Aussage jedoch erheblich, da sie direkt nach der Unterzeichnung der Römischen Protokolle erfolgte. Denn Assoziierung bezog sich nicht auf diejenigen dalmatinischen Gebiete, die als terra irredenta angesehen und tatsächlich in den italienischen Staat inkorporiert wurden.

Die propagandistischen Aussagen zum Imperium unterschieden sich deutlich von der Realität vor Ort, die meistens ganz weit weg von dem angeblichen „humanen“ Umgang mit den Untertanen des Imperiums und ganz nah an der Vorstellung der erbarmungslosen Bekämpfung aller Feinde Italiens war. Trotzdem finden sich immer wieder diverse Versuche, den hegemonial-integrativen Teil des Imperiums umzusetzen, wie er durch die Idee der Romanità zum Ausdruck gebracht wurde. Beides soll für Kroatien noch gezeigt werden.

Da klassische römische Geschichte in Italien vor und während des Faschismus als ein Teil der italienischen Nationalgeschichte gelehrt wurde, ist anzunehmen, dass das Konzept der Romanità einen festen Teil der Weltanschauung eines gebildeten Italieners bildete. Zudem hielten Wissenschaftler aus den Fächern Alte Geschichte, klassische Philologie und Archäologie zahlreiche Vorträge zur Romanità vor diversen Zuhörern - angefangen bei Arbeitern im Rahmen von dopolavoro ${ }^{75}$ Veranstaltungen bis hin $\mathrm{zu}$ Intellektuellen. ${ }^{76}$ Ähnlich wurde nach der Verkündung des Imperiums eine imperiale Pädagogik verbreitet, die die Italiener zu Imperialisten machen sollte, wobei auf diesem Gebiet Faschisten und Katholiken übereinstimmten. ${ }^{77}$ Dies dürfte eine bessere Verbreitung dieser Ideen zur Folge gehabt haben. So spricht einiges dafür, dass die Männer, welche die Besatzungspraxis in Kroatien (und anderswo) maßgeblich beeinflussten und sich in ihrem Handeln immer wieder auf die Romanità beriefen, diese Vorstellungen als einen integralen Teil des italienischen und auch faschistischen Selbstverständnisses gesehen haben. Nachdem das Regime jahrelang das imperiale Erbe von Rom und die damit zusammenhängende Zivilisie-

75 Faschistische Freizeitorganisation, ähnlich der nationalsozialistischen „Kraft durch Freude“. Ausführlich dazu: Vigilante, Elena: L’Opera nazionale dopolavoro: tempo libero dei lavoratori, assistenza e regime fascista, 1925-1943, Bologna 2014.

76 Visser: Fascist Doctrine, insb. S. 15. Obwohl er auf die Notwendigkeit weiterer Studien hinweist, vermutet Visser, dass die Betonung der Romanità die „Koalition“ zwischen Faschismus, reaktionären Strömungen, Monarchisten und konservativen Katholiken wahrscheinlich gestärkt hat. Er erklärt dies mit der Flexibilität des Konzepts, das bei jedem Anklang fand, der anti-demokratische und koloniale Tendenzen hegte, insbesondere in den 1930er Jahren.

77 Bottoni, Riccardo: La „marcia da Roma“ a scuola. Fascisti e cattolici per la „civiltà“ e l'Impero, in: Bottoni, Riccardo (Hg.): L'impero fascista: Italia ed Etiopia (1935-1941), Bologna 2008, S. 321-365, hier S. 365. 
rungsmission des italienischen Volkes propagiert hatte, machten sich die Befehlshaber der Zweiten Armee in Kroatien daran, diese Ideen in die Tat umzusetzen. Die Umsetzung bestand aber, wie auch die Vorstellung während des ganzen ventennio, aus einer Dichotomie zwischen der militaristischen und der versöhnenden Vorstellung vom Imperium. ${ }^{78}$ Vor Ort bedeutete dies, eine unbeugsame Haltung gegenüber den Feinden der faschistischen Vision zu verfolgen und gleichzeitig die Lokalbevölkerung für ein faschistisches Imperium zu gewinnen. Doch anders als in Afrika ging es dort überwiegend nicht um Gebiete, die von Italienern kolonisiert werden sollten. Stattdessen sollte unter Bezug auf das Alte Rom eine imperiale Hierarchie auf dem „gerechten Unterschied“ zwischen den Eroberern und den Eroberten aufgebaut werden. ${ }^{79}$ Daher ist es wichtig, zwischen dem italienischen Kernland und dem restlichen Imperium, dem spazio vitale, zu unterscheiden.

Parallel zu den gerade vorgestellten Idealen, Plänen und Aspirationen musste im ventennio fascista auch eine konkrete Außenpolitik betrieben werden. Diese war durch sehr viele Veränderungen gekennzeichnet - je nachdem, was im Moment als die beste Strategie erschien. Nachdem sich 1918 feindliche österreichische Territorien durch die Schaffung Jugoslawiens in alliierte Gebiete verwandelt hatten, bekam Italien Istrien mit einigen vorgelagerten Inseln und die Stadt Zara statt dem ihm 1915 im Londoner Vertrag versprochenen Dalmatien mit Hinterland bis zur Bucht von Kotor und den meisten der großen Inseln. ${ }^{80}$ Das Gefühl der vittoria mutilata ${ }^{81}$ war geboren und richtete sich in erster Linie gegen Jugoslawien, das umfassendere italienische Gebietsgewinne durch seine schiere Existenz zunichte gemacht hatte. Zudem prägte der „Grenzfaschismus“ mit seinen spezifischen Auseinandersetzungen mit slowenischen und kroatischen Minderheiten die italienische Politik gegenüber Jugoslawien, auch wenn sie in erster Linie durch Mussolini selbst bestimmt wurde. ${ }^{82}$ Sein Handeln war

78 Nelis, Jan: Imperialismo e mito della romanità nella Terza Roma Mussoliniana, in: Forum Romanum Belgicum, 2012, <http://kadoc.kuleuven.be/bhir-ihbr/doc/3_forum_nelis.pdf> (21.4.2019), S. 7.

79 Vgl. Maiocchi: Scienza italiana, S. 184 f.; Costamagna, Carlo: Faschismus. Entwicklung und Lehre, Berlin 1939, S. 214 f. Siehe auch Paladini, Filippo Maria: Mare nostrum, in: Gli italiani in guerra, IV/1, Il Ventennio fascista: dall'impresa di Fiume alla Seconda guerra mondiale (19191940), Turin 2008, S. 615-627, hier S. 623.

80 Cattaruzza: L'Italia e il confine orientale, S. 117-128, 159-164.

81 Vittoria mutilata (verstümmelter Sieg) bezeichnete die Unzufriedenheit Italiens mit seinen territorialen Gewinnen nach dem Ersten Weltkrieg, da nicht alle mit Italien vereinbarten Bestimmungen des Londoner Vertrags von 1915 umgesetzt worden waren.

82 Collotti, Enzo/Labanca, Nicola/Sala, Teodoro: Fascismo e politica di potenza. Politica estera 1922-1939, Mailand 2000, S. 218; Burgwyn, H. James: Italian foreign policy in the interwar period 1918-1940, Westport/London 1997, S. 43. Wörsdörfer, Rolf: Krisenherd Adria 1915-1955. 
von mehreren Überlegungen geleitet: Das jugoslawische Gebiet war als besonders wichtig für italienische Sicherheit erachtet worden ${ }^{83}$ und Jugoslawien stellte einen potentiellen Konkurrenten um Einfluss im ganzen Donau-Balkangebiet dar, den Italien für sich beanspruchte. Zunächst war Mussolinis Politik gegenüber Jugoslawien durch sein Bestreben geleitet, durch außenpolitische Erfolge seine Macht im Inneren zu konsolidieren. Dazu sollte der Freistaat Fiume zerschlagen und die Stadt von Italien annektiert werden. Daher schlug er zunächst eine freundschaftliche Politik gegenüber Jugoslawien ein, die in einige Verträge zwischen Italien und Jugoslawien mündete. ${ }^{84}$

Das Abkommen von Nettuno revidierte schließlich 1925 Teile des Grenzvertrags von Rapallo, indem die freie Stadt Fiume von Italien annektiert wurde, die Außengebiete, d. h. die Stadt Sušak, dem Königreich der Serben, Kroaten und Slowenen zufiel. Das Nettuno-Abkommen regelte die Wirtschaftsbeziehungen zwischen den beiden Ländern sowie Rechte der italienischen Minderheit in Dalmatien. ${ }^{85}$ Diesen Schritten folgte aber eine Verschlechterung der Beziehungen, die sich vor allem in der italienischen Albanienpolitik, aber auch in der Annäherung Italiens an jugoslawische Nachbarn manifestierte. Während Albanien durch die Verträge von 1926 und 1927 zum italienischen Protektorat herabsank, orientierte sich Jugoslawien weiter in Richtung Frankreich. ${ }^{86}$ In Anbetracht der jugoslawischen innenpolitischen Probleme ging Mussolini dazu über, eine Auflösung Jugoslawiens zu favorisieren. Seit 1932 unterstütze Italien den mazedonischen und kroatischen Separatismus nicht nur finanziell, sondern es erlaubte zudem der Ustascha, ihre Basis in Italien aufzubauen und ihre Mitglieder dort auszubilden. Hierbei ist zu betonen, dass die Unterstützung der Ustascha dabei aus pragmatischen und nicht aus ideologischen Gründen erfolgte. ${ }^{87}$ Mussolini wartete auf die „Zersplitterung“ Jugoslawiens, die jedoch weder durch den Ver-

Konstruktion und Artikulation des Nationalen im italienisch-jugoslawischen Grenzraum, München, Paderborn 2004.

83 Iuso, Pasquale: Esercito, guerra e nazione. I soldati italiani tra Balcani e Mediterraneo orientale 1940-1945, Rom 2008, S. 39.

84 Monzali, Luciano: Il sogno dell'egemonia. L'Italia, la questione jugoslava e l'Europa centrale, Florenz 2010, S. 39.

85 Burgwyn: Italian foreign policy, S. 36-40; Collotti/Labanca/Sala: Fascismo e politica di potenza, S. 228-233.

86 Monzali: Il sogno, S. 45-48. Zur italienischen Politik gegenüber Albanien und den Auswirkungen auf die Beziehungen zu Jugoslawien siehe Zamboni, Giovanni: Mussolinis Expansionspolitik auf dem Balkan. Italienische Albanienpolitik vom I. bis zum II. Tiranapakt im Rahmen des italienisch-jugoslawischen Interessenkonflikts und der italienischen ,imperialen“ Bestrebungen in Südosteuropa, Hamburg 1970.

87 Vgl. Cattaruzza: L'Italia e il confine orientale, S. 196 f.; Gobetti: L'occupazione allegra, S. 30; Bucarelli, Massimo: Mussolini e la Jugoslavia (1922-1939), Bari 2006, S. 135-147, 240. 
such eines von der Ustascha initiierten Aufstands in Dalmatien, noch durch die Ermordung des jugoslawischen Königs Aleksandar I., an der die Ustascha zusammen mit der Inneren Mazedonischen Revolutionären Organisation (IMRO) beteiligt war, eintrat. ${ }^{88}$

Mit dem Aufstieg der Nationalsozialisten in Deutschland und dem drohenden Anschluss Österreichs, das Mussolini als einen Garanten für den Status Quo in Europa betrachtete, sowie der italienischen Orientierung in Richtung Afrika änderte sich die aggressive italienische Politik gegenüber Jugoslawien. Ab dem Zeitpunkt sollte Jugoslawien nicht mehr das Opfer italienischer imperialer Pläne werden, sondern sein Bündnispartner, um den deutschen Drang nach Südosten vor Triest und dem Adriatischen Meer zu stoppen. ${ }^{89} \mathrm{Im}$ März 1937 wurde - für die Weltöffentlichkeit überraschend - ein Freundschaftspakt zwischen den beiden Ländern geschlossen. Es sollte ein Balkan-Donau-Block unter italienischer Führung als Gegengewicht zu Deutschland entstehen. Italien erkannte die territoriale Integrität Jugoslawiens an; die Ustascha-Mitglieder und darunter sogar ihre höchsten Funktionäre wurden auf Lipari interniert. Im Anschluss wurde auch ein Wirtschaftsabkommen geschlossen, das den Warenverkehr zwischen den beiden Ländern erhöhen sollte. Doch die Annäherung dauerte nur kurze Zeit und endete mit dem Rücktritt des jugoslawischen Außenministers Stojadinović im Februar 1939. ${ }^{90}$ Danach nahm der italienische Außenminister Ciano die doppelgleisige Politik wieder auf, indem er auf der einen Seite die separatistischen kroatischen Tendenzen unterstützte und auf der anderen Jugoslawien zu überzeugen versuchte, einen Nichtaggressionspakt zu unterschreiben. Doch dieses wollte von seiner strikten Neutralitätspolitik nicht abweichen. ${ }^{91}$

Der Donauraum spielte auch wirtschaftlich für Italien eine wichtige Rolle, obschon italienische Aspirationen auf Jugoslawien in erster Linie politisch motiviert waren. Da der Zugang zum Mittelmeer von England und der Türkei kontrolliert war, blieb Italien nichts anderes übrig, als sich in Richtung Balkan zu orientieren, um Rohstoffe zu beziehen, von denen es noch weniger besaß als Deutschland. So war der Warenaustausch mit Südosteuropa in der zweiten Hälfte der 1930er Jahre gestiegen und für Italien ungefähr genauso wichtig wie für das Deutsche Reich. Umgekehrt war Italien auch ein wichtiger Handelspartner für die südosteuropäischen Staaten. Auch die Struktur des Handels war der

88 Knox, McGregor: Il fascismo e la politica estera italiana, in: Bosworth, Richard/Romano, Sergio (Hg.): La politica estera italiana (1860-1985), Bologna 1991, S. 287-330, hier S. 316, 322 f. 89 Vgl. Burgwyn: Empire, S. 12-14.

90 Cattaruzza: L'Italia e il confine orientale, S. 203; Burgwyn: Italian foreign policy, S. 156. 91 Burgwyn: Empire, S. 14 f. 
deutschen ähnlich, denn Italien führte insbesondere Nahrungsmittel und Rohstoffe ein und Industrieerzeugnisse aus. ${ }^{92}$

Doch die imperialistischen Pläne für den Balkanraum sollten sich bald als illusorisch erweisen. Italien war nicht in der Lage, mit der deutschen ökonomischen Ausbeutung und der Erschließung der Märkte Schritt zu halten, und verlor das politische Tauziehen um Jugoslawien gegen Frankreich. Erst mit dem Beginn des Zweiten Weltkriegs wandte es sich wieder dem Balkan zu. ${ }^{93}$ Doch war dies, wie Luciano Monzali betont, ein Zeichen der italienischen Schwäche. Mussolini versuchte durch die Expansion auf dem Balkan den italienischen spazio vitale nicht etwa vor dem Einfluss des westlichen Kapitalismus, sondern vor seinem deutschen Bündnispartner zu verteidigen und durch den „parallelen“ Krieg seine Position gegenüber dem Deutschen Reich zu stärken. ${ }^{94}$

92 Ulrich von Hassel: Bemerkungen zum Ausgleiche der deutschen und italienischen Wirtschaftsinteressen. Sondergutachten Januar 1941, zit. nach Sundhaussen: Großwirtschaftsraum, S. 52.

93 Cattaruzza: L'Italia e il confine orientale, S. 204.

94 Monzali: Il sogno, S. 82. 